To be presented at $17^{\text {th }}$ International Congress on Applications of Lasers anfFectro-Optics (ICALEO '98), Orlando, Florida, November 16-19, 1998

Neural Network Modeling of Weld Pool Shape in Pulsed-Laser Aluminum WeTd

J. M. Vitek, Y. S. Iskander, and E. M. Oblow

Oak Ridge National Laboratory

Oak Ridge, Tennessee 37831-6376, U. S. A.

"The submitted manuscript has been auhored by a

contractor of the U.S. Government under condract No.

DE-AC05-960R22464. Aceordingly, the U.S.

DE-ACOS-8cope2464. Accordingly, the U.S.

to publish or reproduce the published form of this

contribution, or allow others to do so, for U.S.

Government purposes." 


\title{
Neural Network Modeling of Weld Pool Shape in Pulsed-Laser Aluminum Welds
}

\author{
J. M. Vitek, Y. S. Iskander, and E. M. Oblow \\ Oak Ridge National Laboratory \\ Oak Ridge, Tennessee 37831-6376, U. S. A.
}

\begin{abstract}
$\underline{\text { Abstract }}$

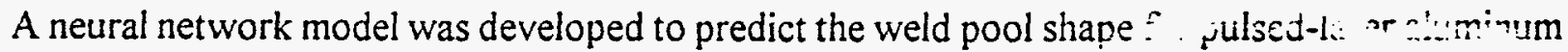
welds. Several different network architectures were examined and the optimum architecture wai identified. The neural network was then trained and, in spite of the small size of the training data set, the network accurately predicted the weld pool shape profiles. The neural network output was in the form of four weld pool shape parameters (depth, width, half-width, and area) and these were converted into predicted weld pool profiles with the use of the actual experimental pool profiles as templates. It was also shown that the neural network model could reliably predict the change from conduction-mode type shapes to keyhole-mode shapes.

\section{Introduction}

Weld pool shape is critically important in terms of determining the quality of a weld. For example, the depth of penetration is often the most important feature that determines whether a weld is acceptable or not. Over the last two decades, many fundamental studies have tried to develop models that predict the weld pool shape from first principles ${ }^{1-8}$. These models have become increasingly sophisticated over the years and have been very useful in providing a better, more fundamental understanding of the factors that affect the weld pool shape. However, as the models have become more advanced, they have also become more cumbersome to use and require ever-increasing computational times. Thus, they are often not suitable for simple parametric studies or for providing guidelines for determining appropriate process parameters. Furthermore, they are not particularly amenable to in-process applications such as control loops where simplicity and rapid response time are required. For the use of models in real-time process applications, the ability to make instantaneous predictions is desirable and often essential.
\end{abstract}

One solution for providing real-time predictions of weld pool shape (as well as other weld attributes such as cracking propensity or weld properties) is the utilization of neural network models. 


\section{DISCLAIMER}

Portions of this document may be illegible in electronic image products. Images are produced from the best available original document. 


\section{DISCLAIMER}

This report was prepared as an account of work sponsored by an agency of the United States Government. Neither the United States Government nor any agency thereof, nor any of their employees, make any warranty, express or implied, or assumes any legal liability or responsibility for the accuracy, completeness, or usefulness of any information, apparatus, product, or process disclosed, or represents that its use would not infringe privately owned rights. Reference herein to any specific commercial product, process, or service by trade name, trademark, manufacturer, or otherwise does not necessarily constitute or imply its endorsement, recommendation, or favoring by the United States Government or any agency thereof. The views and opinions of authors expressed herein do not necessarily state or reflect those of the United States Government or any agency thereof. 
These models are empirically based but they can be quite sophisticated while still maintaining the essential features of ease of use and rapid response time. Several recent papers have addressed the issue of predicting weld shape with neural networks in arc-welding ${ }^{9-11}$ and laser spot-welding ${ }^{12,13}$. The present paper describes the application of neural network modeling to the problem of predicting weld pool shape in pulsed Nd:YAG laser aluminum welds. It is demonstrated that neural network predictions can be quite accurate, even if limited data to train the network are available. The use of neural networks in predicting weld pool shape (or weld properties) is quite general and can be applied to any welding process, provided the proper data for training the neural network are available.

Recently, a neural network model for the prediction of weld pool shape as a function of welding parameters in pulsed Nd:YAG laser aluminum welds was developed ${ }^{14}$. In that study, the neural network was trained on an initial set of data and was tested on welds that were produced in a second round of welds. However, welds made in the two rounds were very different in character in that the first-round welds exhibited characteristics of conduction-mode welds (broad, less penetration) while the second-round welds were more like keyhole welds (narrower and deeper). Not surprisingly, the reliability of the neural network predictions was limited because the network was trained on one type of weld and tested on another. In the present study, the neural network was trained on the combined data from both weld rounds. In this way, the ability of the neural network to predict significantly different weld pool profiles was more meaningfully evaluated.

\section{Neural Networks - Background}

Neural networks are based on a simple scheme in which inputs are related to outputs by a system of interconnected nodes. A very simple description of the concept behind neural networks is given below. There is extensive literature on the theory behind neural networks. The reader is referred to other publications for more details ${ }^{15,16}$. A network structure consists of three layers of nodes: input nodes, hidden nodes, and output nodes. These nodes are "connected" to each other so that the value of one node will affect the value of another. The relative influence that one node has on another one is specified by the "weight" that is assigned to each connection. A schematic diagram of a simple neural network is shown in Figure 1. The three layers are marked in the diagram. In principle, the hidden layer can consist of multiple sub-layers but in this study only one hidden layer was considered.

In the schematic example of Figure 1 , the input layer has three nodes,

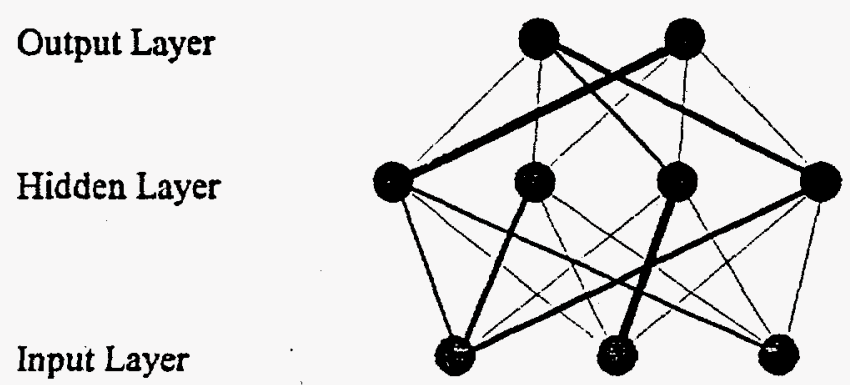

Figure 1: Schematic diagram showing the multiple layer structure of a neural network and the inter-connectivity between the nodes of the network. representing three input variables, while the output layer consists of two nodes, corresponding to two output variables. In addition, the hidden layer has four nodes, as shown in the diagram. The different weights for the node connections are depicted by different line thicknesses.

The network is based on the mathematical relationships that 
follow. With input node values, $I_{i}$, for all $i$ input nodes, the sum $S_{j}^{H}$ at hidden node $j$ is given by

$$
S_{j}^{H}=\sum_{i} I_{i} w_{i j}+I_{0}
$$

where $w_{i j}$ are the weights for the connections between all input nodes $i$ and hidden nodes $j$, and $I_{0}$ is a constant known as the bias. This sum is calculated for each of the $j$ hidden nodes. The value of the hidden node is then calculated from the sums with the use of a transfer function. In the current study, sigmoid transfer functions were used. Therefore, the value of each hidden node, $H_{j}$, is given by

$$
H_{j}=\frac{1}{1+e^{-S_{j}^{H}}}
$$

where $S_{j}^{H}$ is given by Equation (1). The same procedure is used to sum the contributions from each of the hidden nodes to obtain a sum for each output node $k$ as given by

$$
S_{k}^{O}=\sum_{j} H_{j} w_{j k}+H_{0}
$$

where $w_{j k}$ are the weights connecting hidden nodes $j$ with output nodes $k$. The values for $H_{j}$ are given by Equation (2) while $H_{0}$ is a constant bias. Finally, the sums at the output nodes are converted in output values, $O_{k}$, by means of another (sigmoid) transfer function

$$
O_{k}=\frac{1}{1+e^{-S_{k}^{O}}}
$$

Once again, the values for $S_{k}^{o}$ are obtained from Equation(3). In addition, the actual input and output data are usually normalized so that a conversion to $I_{i}$ values and from $O_{k}$ values is also needed.

Neural network training is carried out with the use of a training data set that contains sets of inputs and corresponding outputs. By means of an optimization scheme, the neural network is developed by comparing the predicted output values with the actual outputs and adjusting the weights to minimize the prediction error. For example, when applied to weld shape modeling, the input nodes may correspond to weld process conditions such as welding speed, power, and material thickness while the output nodes may represent weld pool shape parameters such as width and penetration depth. Through the learning process, which involves thousands of iterations, a complicated set of empirical relationships between input and output variables is developed. Eventually, with minimal user influence, the network "learns" a scheme in which outputs are associated with the inputs. In the present analysis, a feed-forward network with a back-propagation learning scheme was utilized ${ }^{16}$.

\section{Experimental Conditions}

Autogenous, pulsed Nd:YAG laser welds were made on 3-mm-thick sheet of aluminum alloy 5754. A range of welding conditions was examined and the parameters are listed in Table 1 . The ten conditions on the left of Table 1 were from the first round of welds (and were used to train the earlier neural network ${ }^{14}$ ) while the thirteen conditions on the right were from the second round of welds. In the present study, all 23 conditions were used to train the neural network. All welds were made at approximately 4 pulses $/ \mathrm{mm}$ in order to insure sufficient overlap of the pulses. The average power 
was varied from 50 to $244 \mathrm{~W}$ to include a wide range of power levels and corresponding pool shapes and sizes without reaching full penetration. The aim was to cover typical welding conditions used in practice. In all cases, the laser beam was focused on the top surface. The welds were sectioned and five transverse cross-sections were examined metallographically from each weld. Average shape parameters from the five transverse views were used to compensate for the variation in weld profile shape due to the pulsed nature of the welding process.

\section{Weld Pool Shape Characterization}

In order to predict weld pool profiles, it was first necessary to identify parameters that characterize the weld pool shape. One approach is to describe the cross-section profile in terms of an analytical function. However, this has several drawbacks. First, the experimental cross-sections included a wide range of shapes and therefore a simple geometric function would be inappropriate. Second, the number of parameters in an analytical description would have to be limited since the limited amount of data available for training does not justify a model with a large number of adjustable parameters. Finally, the use of an analytical function to describe the weld pool shape would introduce a bias based on the choice of the analytical function. Therefore, four physical parameters relating to the actual weld pool shape were used instead of an analytical function.

The four parameters describing the actual shape of the weld pool cross-section were penetration depth, width (at the top of the weld), width at half penetration (referred to as "half-width"), and total area. These four parameters were evaluated from the experimental weld pool cross-sections, as shown schematically in Figure 2. The top surface of the welds was often irregular (see Figure 2). This presented a problem when ascertaining the area of the welds. It was decided to use the actual

Table 1: Laser welding conditions for alloy 5754.

\begin{tabular}{|ccccc||ccccc|}
\hline ID & $\begin{array}{c}\text { Weld } \\
\text { Speed } \\
(\mathrm{mm} / \mathrm{s})\end{array}$ & $\begin{array}{c}\text { Pulse } \\
\text { Energy } \\
\text { (Joules) }\end{array}$ & $\begin{array}{c}\text { Average } \\
\text { Power } \\
\text { (Watts) }\end{array}$ & $\begin{array}{c}\text { Pulse } \\
\text { Duration } \\
(\mathrm{msec})\end{array}$ & $\begin{array}{c}\text { ID } \\
\text { Speed } \\
\text { (mm/s) }\end{array}$ & $\begin{array}{c}\text { Pulse } \\
\text { Energy } \\
\text { (Joules) }\end{array}$ & $\begin{array}{c}\text { Average } \\
\text { Power } \\
\text { (Watts) }\end{array}$ & $\begin{array}{c}\text { Pulse } \\
\text { Duration } \\
\text { (msec) }\end{array}$ \\
\hline 1 & 6.38 & 2 & 51 & 2.2 & 11 & 3 & 4.17 & 50 & 2.2 \\
2 & 6.38 & 2.9 & 74 & 2.2 & 12 & 3 & 6.25 & 75 & 2.2 \\
3 & 6.38 & 4.1 & 101 & 2.2 & 13 & 3 & 8.33 & 100 & 2.2 \\
4 & 10.2 & 3 & 125 & 2.2 & 14 & 5 & 5 & 100 & 2.2 \\
5 & 10.2 & 3.5 & 158 & 2.2 & 15 & 5 & 7.5 & 150 & 2.2 \\
6 & 10.2 & 4.1 & 165 & 2.2 & 16 & 5 & 9.05 & 181 & 2.2 \\
7 & 10.2 & 5.5 & 203 & 2.2 & 17 & 6.38 & 4.0 & 100 & 2.2 \\
8 & 2.55 & 11.3 & 123 & 7.5 & 18 & 7.65 & 3.33 & 100 & 2.2 \\
9 & 3.83 & 9.5 & 190 & 7.5 & 19 & 7.65 & 5 & 150 & 2.2 \\
10 & 3.83 & 13.2 & 196 & 7.5 & 20 & 7.65 & 6.67 & 200 & 2.2 \\
& & & & & 21 & 7.65 & 8.13 & 244 & 2.2 \\
& & & & & 22 & 10.2 & 3.95 & 158 & 2.2 \\
& & & & & & & \\
& & &
\end{tabular}


weld cross-section areas, without arbitrarily ignoring protuberances or depressions on the top surface. However, when using the output from the neural network model to construct a predicted weld pool cross-section, a flat top surface was imposed.

Finally, it was necessary to relate the four shape parameters to an actual weld profile. This was accomplished by using the experimental weld profiles as templates. The output shape parameters from the neural network were compared to the entire set of experimentally measured profile parameters and the closest match was identified. Then, the corresponding experimental weld profile was scaled appropriately so that the final profile depth and width corresponded to the predicted values. In this way, the predicted weld shape resembled the actual experimental weld cross-sections and there was no need to impose an arbitrary analytical function to describe the complex profiles. The weld profile template library was relatively extensive because all five cross-sections that were taken from each weld were utilized.

\section{Network Development}

The calculations were carried out with the use of a commercial software package, Neural Works Professional II/PLUSTM ${ }^{17}$. The development of the network was broken down into four stages. First, the input and output parameters were identified. In principle, it is desirable to choose input parameters that relate directly to the weid process conditions. Therefore, four process variables (speed, average power, pulse energy, pulse duration) were chosen as input nodes. However, there was another, unknown variable that changed from the first round of welds to the second and led to the change in weld shape character from conduction type to keyhole type. A fifth input node was added to distinguish the two rounds and account for the unknown process condition that changed. The output nodes corresponded to the four weld pool parameters, as explained earlier.

The second step was to determine the optimum network architecture, and specifically the optimum number of hidden nodes. As the number of hidden nodes is increased, the network is better able to identify a pattern between the inputs and outputs in the learning data set. However, if the number

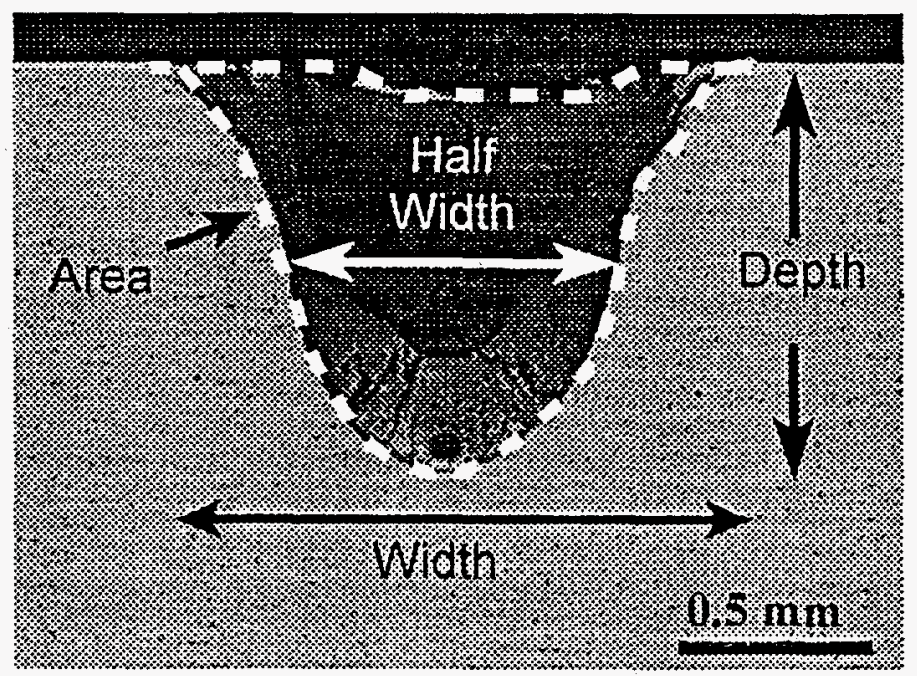

Figure 2: Micrograph of typical weld pool protile and parameters measured for each weld. of hidden nodes is too large, then the network tends to memorize the input-output pairings in the learning data set rather than identify relationships and, as a result, the network is less accurate in predicting weld pool shapes for new data. The optimum number of hidden nodes is controlled to a large extent by the size of the learning data set. If an extensive learning set is available, then many hidden nodes can be utilized effectively. To determine the optimum architecture, the complete 23-point data set was subdivided into pairs of training and testing sets, with 20 and 3 points, respectively. Five such pairs were created, using randomly chosen data points, and 
networks were developed for each training subset. The learnability and predictability of the networks were measured by the root mean square (RMS) error of the network output for the learning and testing data sets, respectively. A lower RMS corresponds to better learnability or predictability. Average RMS values for the network output for the five pairs of learning and testing data sets were calculated for each network configuration. Network configurations with one to six hidden nodes were examined. A plot of the RMS error as a function of the number of hidden nodes is given in Figure 3 . The learning RMS error decreases monotonically with increasing number of hidden nodes, as expected. However, the prediction RMS error is a minimum with two hidden nodes. For all other configurations that were examined, the RMS error was greater and the network's ability to predict behavior was diminished. This same behavior, i.e., the minimum prediction

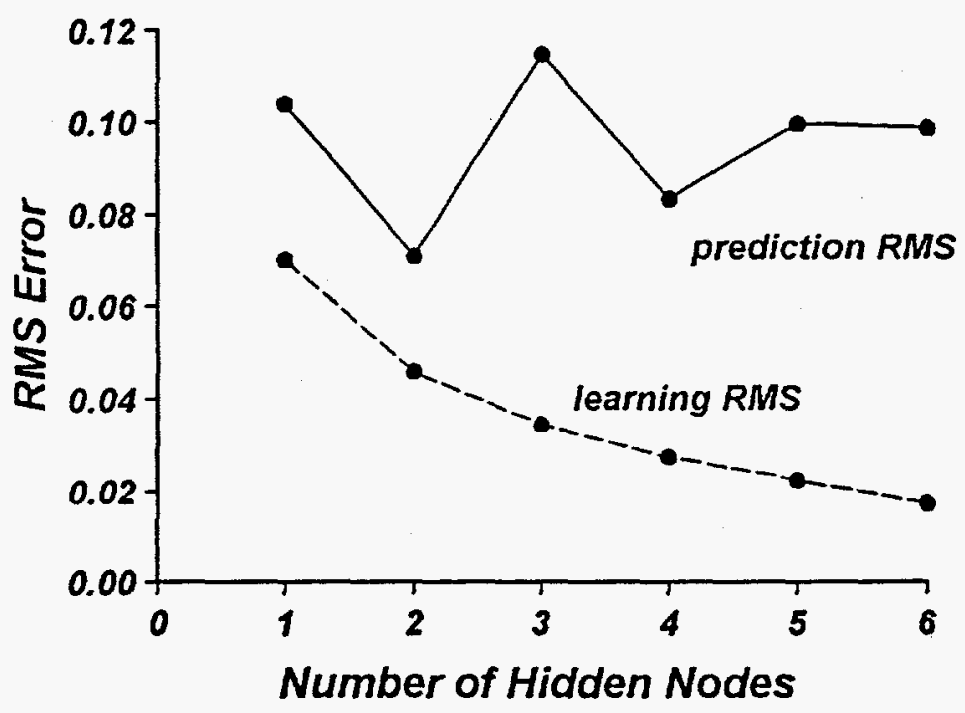

Figure 3: Plot of the average RMS error as a function of the number of hidden nodes for the learnability and predictability of the network.

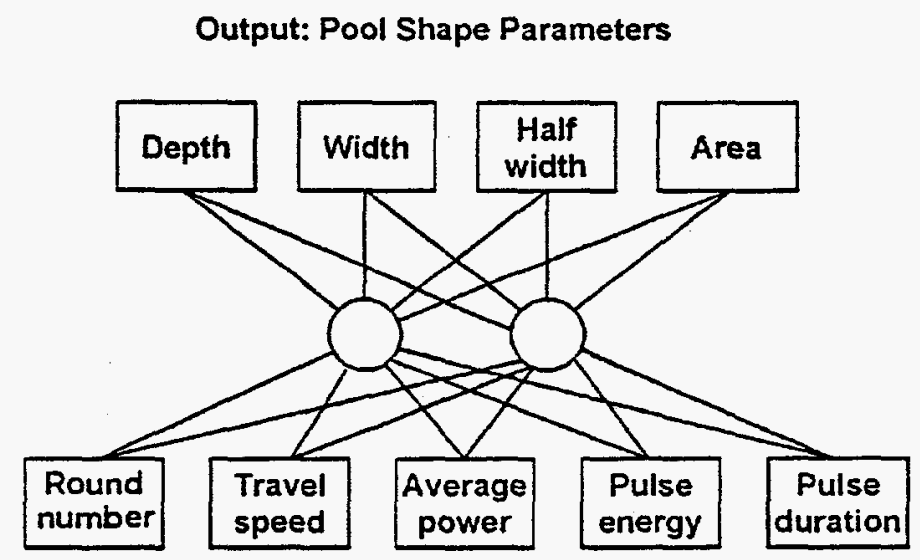

Input: Weld Process Parameters RMS for two nodes, was also found for a second set of calculations with different starting weights for the network development. Therefore, it was concluded that a network architecture with two hidden nodes was optimal. The final network architecture is shown in Figure 4.

With the optimum network configuration identified, the next step was to develop the "best" network. For this stage, the entire data set of 23 points was used. Different starting values for the network weights were used and the networks were trained until further training did not yield any improvement in the RMS error. Eighty different sets of starting weight values were tested and the best of the resultant networks was found. It should be noted that additional testing with different starting weights would likely yield an even better network since the nature of neural network analysis is such that an absolute best network is never found. However, the differences in RMS error between the top five networks was minimal and this was taken as an indication that further training was not likely to yield any significant improvement.

Figure 4: Final neural network architecture. 
The final step was to assess the ability of the best network to predict weld pool shape for new process conditions. This was accomplished in the following manner. One data point was removed from the total of 23 and a new network was taught with the remaining 22 points, using the optimal architecture and starting weight values identified earlier. Then, the network was tested on the one point that was omitted. In this way, a true prediction was obtained since the test point was new to the network. This procedure was repeated twenty three times, to test each data point separately.

\section{$\underline{\text { Results and Discussion }}$}

As discussed in detail above, the optimum neural network architecture was found to include two hidden nodes. With this configuration, the results of the predictability testing provide a quantitative measure of the accuracy with which the network predicts the weld pool shape parameters. In the predictability test, the neural nets that are developed are basically the same as the best network, with the only difference being that each net is trained on a different combination of 22 of the total 23 data points. The predictability test results for all 23 data points are summarized in Table 2. Prediction errors are given in terms of both absolute and relative values. From the table, it can be concluded that the predicted shape parameters are in relatively good agreement with the experimental values. The absolute errors are less than $0.15 \mathrm{~mm}, 0.25 \mathrm{~mm}$, and $0.15 \mathrm{~mm}^{2}$ for depth, width, and area, respectively, in nearly all cases. Percent errors are $20 \%$ or less in most cases, except for the smallest weld pool sizes where the percent errors tend to be large even if the absolute errors are small.

A visual comparison of predicted pool shapes vs experimental shapes .. conditions 9,13 , and 20 in Table 2 . The predicted pool shape is bold while the five corresponding experimental cross-sections are shown by the fainter lines. It can be seen that the predicted pool shapes agree very well with the experimental pool shapes. For condition 9 , the prediction errors in Table 2 are greater than the average errors and yet the prediction falls well within the range of pool shapes that was found experimentally. While condition 9 in Figures 5 is from the first set of laser runs, conditions 13 and 20 in Figure 5 are from the second set of welds. The different weld characteristics, namely the wider and broader shapes from the first round and the deeper, more keyhole-like shape in the second round, are reproduced by the neural network model. For comparison, predictions from the earlier neural network model ${ }^{1+}$ for conditions 13 and 20 are shown in Figure 6. It can be seen that the earlier model predicted the weld pool shape reasonably well for condition 20 but the prediction for condition 13 was not very good. The inaccuracy in the prediction was due to the fact that the earlier neural network was trained on only the first set of welds. In the present case, the neural network accuracy is outstanding for both types of welds. This is attributable to the fact that this newer network was trained on data that included both the wide weld shapes as well as the keyhole-type shapes.

The objective of this study was two-fold. The first objective was to demonstrate the ability of neural network models to predict weld pool shapes. The results in Figure 5 show that reliable predictions are possible for a wide range of pool shapes and weld conditions. This was achieved in spite of the fact that the data set was relatively small in size, containing only 23 different weld process conditions. The second objective was to show that the shortcomings of the earlier neural network model were due to the fact that the weld pool shapes in the training data set were of an entirely different nature than the shapes in the test set. In the present study, where both types of pool profiles 
Table 2: $\quad$ Experimental and predicted laser pool shape dimensions for conditions in Table 1. $\mathrm{D}=\operatorname{depth}(\mathrm{mm}), \mathrm{W}=$ width $(\mathrm{mm}), \mathrm{A}=$ area $\left(\mathrm{mm}^{2}\right)$. Half-width omitted due to space limitations.

\begin{tabular}{|c|ccc|ccc|ccc|cc|cc|}
\hline & \multicolumn{3}{|c|}{ Experimental } & \multicolumn{3}{c|}{ Predicted } & \multicolumn{3}{c|}{ \% Error } & \multicolumn{3}{c|}{ Absolute Error } \\
\hline ID & $\mathrm{D}$ & $\mathrm{W}$ & $\mathrm{A}$ & $\mathrm{D}$ & $\mathrm{W}$ & $\mathrm{A}$ & $\mathrm{D}$ & $\mathrm{W}$ & $\mathrm{A}$ & $\mathrm{D}$ & $\mathrm{W}$ & $\mathrm{A}$ \\
\hline 1 & 0.10 & 0.61 & 0.06 & 0.21 & 0.86 & 0.10 & 110 & 41 & 67 & 0.11 & 0.25 & 0.04 \\
2 & 0.20 & 0.87 & 0.13 & 0.19 & 0.82 & 0.09 & 5 & 6 & 31 & 0.01 & 0.05 & 0.04 \\
3 & 0.41 & 0.98 & 0.23 & 0.27 & 1.04 & 0.18 & 34 & 6 & 22 & 0.14 & 0.06 & 0.05 \\
4 & 0.17 & 0.89 & 0.12 & 0.23 & 0.88 & 0.12 & 35 & 1 & 0 & 0.06 & 0.01 & 0.00 \\
\hline 5 & 0.16 & 0.94 & 0.13 & 0.27 & 0.98 & 0.17 & 69 & 4 & 31 & 0.11 & 0.04 & 0.04 \\
6 & 0.24 & 1.03 & 0.17 & 0.28 & 1.06 & 0.19 & 17 & 3 & 12 & 0.04 & 0.03 & 0.02 \\
7 & 0.36 & 1.22 & 0.28 & 0.46 & 1.19 & 0.35 & 28 & 3 & 25 & 0.10 & 0.03 & 0.07 \\
8 & 0.66 & 1.35 & 0.50 & 0.69 & 1.24 & 0.51 & 5 & 8 & 2 & 0.03 & 0.11 & 0.01 \\
\hline 9 & 0.43 & 1.18 & 0.32 & 0.51 & 1.36 & 0.41 & 19 & 15 & 28 & 0.08 & 0.18 & 0.09 \\
10 & 0.97 & 1.57 & 0.76 & 0.88 & 1.28 & 0.62 & 9 & 18 & 18 & 0.09 & 0.29 & 0.14 \\
11 & 0.81 & 1.00 & 0.40 & 0.67 & 0.75 & 0.38 & 17 & 25 & 5 & 0.14 & 0.25 & 0.02 \\
12 & 1.31 & 1.06 & 0.88 & 1.16 & 1.00 & 0.70 & 11 & 6 & 20 & 0.15 & 0.06 & 0.18 \\
\hline 13 & 1.51 & 1.03 & 1.03 & 1.49 & 1.22 & 0.96 & 1 & 18 & 7 & 0.02 & 0.19 & 0.07 \\
14 & 0.65 & 0.92 & 0.34 & 0.79 & 0.93 & 0.47 & 22 & 1 & 38 & 0.14 & 0.01 & 0.13 \\
15 & 1.22 & 1.25 & 0.71 & 1.35 & 1.13 & 0.90 & 11 & 10 & 27 & 0.13 & 0.12 & 0.19 \\
16 & 1.43 & 1.14 & 1.03 & 1.54 & 1.34 & 1.02 & 8 & 18 & 1 & 0.11 & 0.20 & 0.01 \\
\hline 17 & 0.46 & 0.90 & 0.25 & 0.45 & 0.86 & 0.25 & 2 & 4 & 0 & 0.01 & 0.04 & 0.00 \\
18 & 0.28 & 0.85 & 0.18 & 0.29 & 0.82 & 0.14 & 4 & 4 & 22 & 0.01 & 0.03 & 0.04 \\
19 & 0.55 & 1.06 & 0.33 & 0.52 & 0.94 & 0.31 & 5 & 11 & 6 & 0.03 & 0.12 & 0.02 \\
20 & 0.81 & 1.26 & 0.51 & 0.92 & 1.11 & 0.60 & 14 & 12 & 18 & 0.11 & 0.15 & 0.09 \\
\hline 21 & 1.32 & 1.16 & 0.88 & 1.02 & 1.33 & 0.72 & 23 & 15 & 18 & 0.30 & 0.17 & 0.16 \\
22 & 0.31 & 0.88 & 0.21 & 0.29 & 0.97 & 0.18 & 6 & 10 & 14 & 0.02 & 0.09 & 0.03 \\
23 & 0.45 & 1.00 & 0.28 & 0.37 & 1.11 & 0.27 & 18 & 11 & 4 & 0.08 & 0.11 & 0.01 \\
\hline & & & & & & & & & & & & \\
\hline & & & Average & & & 21 & 11 & 18 & 0.09 & 0.11 & 0.06 \\
\hline
\end{tabular}

were combined in the training data set, the change in weld pool shape could be treated in a more accurate fashion. These results show that neural networks provide a suitable means for modeling weld pool shapes as a function of weld process parameters. Neural network models have the added advantage that they are rapid, providing virtually instantaneous results, and therefore they may be ideally suited for integration into process control routines.

\section{$\underline{\text { Summary }}$}

A neural network model has been developed that reliably predicts the weld pool profile in pulsedlaser aluminum welds. The present model is an improvement over an earlier one in that the change 


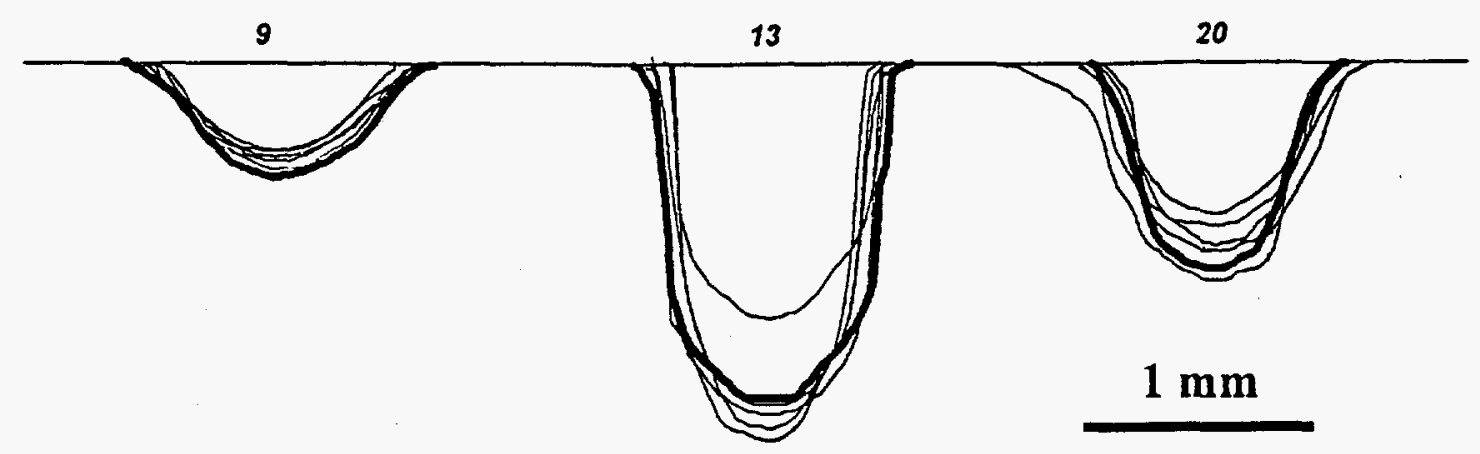

Figure 5: Predicted weld pool shapes (bold) superimposed over experimental pool profiles. The identification numbers refer to Table 2 .
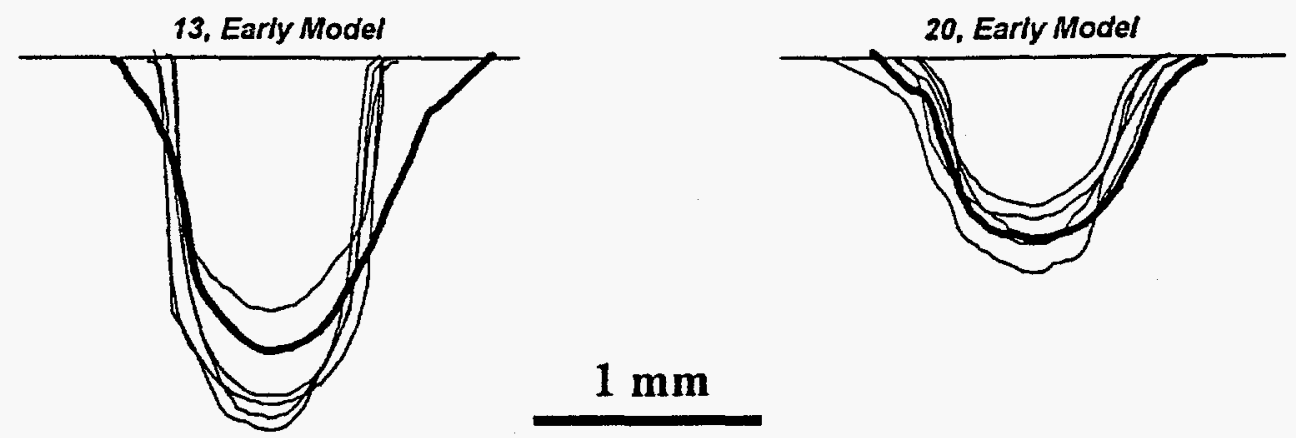

Figure 6: Predicted weld pool profiles from earlier neural network model ${ }^{14}$.

in nature from conduction-mode to keyhole-mode weld pool shapes is taken into account. The neural network model is accurate over a wide range of process conditions, in spite of the fact that the training data set is relatively small.

\section{Acknowledgments}

This research was sponsored by the Laboratory Directed Research and Development Program of Oak Ridge National Laboratory, managed by Lockheed Martin Energy Research Corp. for the U. S. Department of Energy under contract DE-AC05-960R22464. The authors would like to acknowledge the support of Sandia National Laboratories, and Dr. P. W. Fuerschbach, for providing the weld samples. The authors would also like to thank Drs. E. T. Kozeschnik and S. S. Babu for their reviews of the manuscript.

\section{$\underline{\text { References }}$}

1. G. M. Oreper and J. Szekely. "Heat and Fluid Flow Phenomena in Weld Pools." J. Fluid Mech. Vol. 147: (1984). pp. 53-79.

2. C. Chan, J. Mazumder and M. M. Chen. "A Two-Dimensional Transient Model for Convection in Laser Melted Pools." Metall Trans A Vol. 15A: (1984). pp. 2175-2184. 
3. S. Kou and Y. H. Wang. "Weld Pool Convection and Its Effect." Weld. J. Vol. 65: (1986). pp. $63 \mathrm{~s}-70 \mathrm{~s}$.

4. A. Paul and T. DebRoy. "Free Surface Flow and Heat Transfer in Conduction Mode Laser Welding." Metall Trans B Vol. 19B: (1988). pp. 851-858.

5. T. Zacharia, S. A. David, J. M. Vitek and T. DebRoy. "Weld Pool Development during GTA and Laser Beam Welding of Type 304 Stainless Steel, Part I - Theoretical Analysis." Weld. J. Vol. 68: (1989). pp. 499s-509s.

6. T. Zacharia, S. A. David, J. M. Vitek and T. DebRoy. "Weld Pool Development during GTA and Laser Beam Welding of Type 304 Stainless Steel, Part II - Experimental Correlation." Weld. J. Vol. 68: (1989). pp. 510s-519s.

7. R. T. C. Choo and J. Szekely. "The Effect of Gas Shear Stress on Marangoni Flows in Arc Welding." Weld. J. Vol. 70: (1991). pp. 223s-233s.

8. A. Matsunawa. (1992) "Modeling of Heat and Fluid Flow in Arc Welding" in International Trends in Welding Science and Technology. Eds S. A. David and J. M. Vitek. ASMInternational, Materials Park, Ohio. pp. 3-16.

9. U. Dilthey, T. Reichel, and J. Heidrich. (1997) "Classification of Weld Bead Geometry in GMA Welding with Neural Networks" in Mathematical Modelling of Weld Phenomena. Ed. H. Cerjak. Institute of Materials, London. pp 390-402.

10. J. S. Noruk. (1997) "Gas Metal Arc Penetration Welding Development Utilizing Neural Nets" in Proceedings Seventh International Conference on Computer Technology in Welding. NIST Special Pub 923. Ed. T. Siewert. U.S. Government Printing Office, Washington, D.C. pp 54-62.

11. B. Chan, J. Pacey and M. Bibby. (1997) "Estimating Optimal Welding Parameters Using Artificial Neural Network Technology" ibid. pp 518-528.

12. W.-S. Chang, S.-J. Na, H.-S. Moon, S.-J. Hong and H.-S. Kang. (1997) "Prediction of Laser Spot Weld Shape by Numerical Analysis and Neural Network" ibid. pp 213-221.

13. K. Matsuyama. (1997) "Nugget Size Sensing of Spot Weld Based on Neural Network Learning" ibid. pp 486-495.

14. J. M. Vitek, Y. S. Iskander, E. M. Oblow, S. S. Babu, S. A. David, P. W. Fuerschbach, H. B. Smartt, D. P. Pace and C. R. Tolle. "Neural Network Modeling of Pulsed-Laser Weld Pool Shapes in Aluminum Alloy Welds." (1998) to be published in proceedings of 5th Intl Conf on Trends in Welding Research, Pine Mountain, Georgia, June 1-5, 1998.

15. D. E. Rumelhart, B. Widrow and M. A. Lehr. "The Basic Ideas in Neural Networks." Comm. ACM Vol. 37: (1994). pp. 87-92.

16. C. M. Bishop. "Neural Networks and Their Applications." Rev. Sci. Instr. Vol. 65; (1994). pp. 1803-1832.

17. NeuralWare, Inc. Pittsburgh, Pennsylvania (1995).

Drs. J. M. Vitek and E. M. Oblow are Research Staff Members in the Metals and Ceramics Division and the Computational Sciences Division, respectively, at Oak Ridge National Laboratory (ORNL). Mr. Y. S. Iskander was a summer research fellow at ORNL and is currently a student at the University of Tennessee - Chattanooga in the Electrical Engineering Department. 